\title{
A clinico hematological correlation of autoimmune hemolytic anemia and its clinical implication
}

\author{
Goswami P.R ${ }^{1}$, Chaudhary S.B ${ }^{2}$ \\ ${ }^{1}$ Dr. Parth R. Goswami, Tutor ${ }^{2}$ Dr. Shweta B. Chaudhary, Resident, both authors are affiliated with department of \\ Pathology, Government Medical College, Bhavnagar, Gujrat, India
}

Address for Correspondence: Dr. Parth R. Goswami, “102” Sangath flat, Shilpinagar, Kalanala, Bhavnagar. Email: goswamiparth42@gmail.com

\begin{abstract}
Introduction: Autoimmune hemolytic anemia characterized by production of antibodies that attach to Red cells resulting in their destruction causing anemia. AIHA could be primary or secondary to some other cause. The positive DCT is hallmark for diagnosis of AIHA. Aim of Study: To perform clinical and hematological study of AIHA and from available data to derive necessary conclusion for accurate diagnosis of AIHA. Material and Methods: The prospective study was carried out in blood bank at tertiary care hospital in positive DCT cases from suspected AIHA cases. The detail history was taken, clinical presentation studied and necessary laboratory investigations like peripheral smear examination, Reticulocyte count, Serum bilirubin, Serum LDH etc done and all data tabulated and conclusion was made for diagnosing AIHA accurately. DCT was performed both manually and using gel card technology. Conclusion: Females and age group between 20 to 30 have more predilections for developing AIHA. Secondary cases are more common and severity of presentation was aggressive in primary cases as compared to secondary. Such type of study helpful in diagnosis AIHA accurately and delay in treatment can be avoided and awareness can be created .
\end{abstract}

Key words : Autoimmune hemolytic anemia, DCT, Primary AIHA, Secondary AIHA.

\section{Introduction}

Autoimmune hemolytic anemia characterized by production of antibodies that attach to Red cells resulting in their destruction causing anemia. Antibodies are of two types depending on their avidity for red cells at low temperature 4'C (cold antibodies) or at body temperature $37^{\prime} \mathrm{C}$ (Warm antibodies) [1].

Warm antibodies that react at $37^{\prime} \mathrm{C}$ are IG $\mathrm{G}$ type and antibody coated red blood cells sequestrated in spleen and liver, resulting in extra vascular hemolysis. While cold antibodies that are effective at 4'C are IG M type and can activate complement and leads intravascular hemolysis [1,2]. As hemolysis occurs in autoimmune hemolytic anemia, it will show positive coomb's test (Direct coomb's test) which is the diagnostic test for it. [3] Coomb's et al. in 1945, showed that AHG test useful in detecting antibodies to human globulin \&

Manuscript received $24^{\text {th }}$ September 2016

Reviewed: $5^{\text {th }}$ October 2016

Author Corrected: $18^{\text {th }}$ October 2016

Accepted for Publication $31^{\text {st }}$ October 2016 complement that coat RBC in hemolytic anemia [4]. The clinical features include: weakness, dyspnea on exertion, fatigue, jaundice, splenomegaly, Pallor, dizziness, fever, bleeding, weight loss, abdominal pain etc $[1,5]$.The incidence has been discussed in discussion portion of this article.

\section{Aim of Study}

To perform clinical and hematological study of AIHA and from available data to derive necessary conclusion for accurate diagnosis of AIHA.

\section{Materials and Methods}

The prospective study carried out on patients that are referred to blood bank at tertiary care hospitals for investigating suspected cases AIHA.

The study was conducted from $1^{\text {st }}$ January 2015 to June 2016. 
The tests that were performed are Direct coomb's test (DCT) and Indirect coomb's test (ICT) by both manual as well as Gel card technique. The ICT positive cases investigated further by doing antibody titration.

The detail history along with clinical features taken for all patients and physical examination was also done. Patients with $\mathrm{Rh}$ and $\mathrm{ABO}$ incompatibility and blood transfused patient in last six month were excluded from this study.

After performing DCT and ICT, laboratory investigations like $\mathrm{CBC}$, retic count, peripheral smear examination, serum LDH estimation and bilirubin estimation were done. All records were tabulated and final conclusion was made regarding clinicohematological study of AIHA.

\section{Results}

Total 60 DCT positive cases were studied and investigated. The mean age was found to be 27 year and among this 38 patients were female and 22 were males.

Among these 60 cases etiologically 34 cases were due to secondary to other causes while 26 cases were primary AIHA.

Table No-.1: Etiology of Autoimmune hemolytic anemia

\begin{tabular}{|c|c|c|c|c|c|c|c|c|c|c|}
\hline $\begin{array}{c}\text { Primary } \\
\text { AIHA } \\
\text { cases }\end{array}$ & $\begin{array}{c}\text { Second } \\
\text { ary } \\
\text { AIHA } \\
\text { cases }\end{array}$ & Tuberculosis & HIV & $\begin{array}{c}\text { Connective } \\
\text { tissue } \\
\text { disorders } \\
\text { like SLE }\end{array}$ & AML & CML & CLL & $\begin{array}{c}\text { Drug } \\
\text { induced }\end{array}$ & $\begin{array}{c}\text { IT } \\
\text { P }\end{array}$ & $\begin{array}{c}\text { Malari } \\
\mathbf{a}\end{array}$ \\
\hline 26 & 34 & 07 & 04 & 03 & 02 & 03 & 01 & 06 & 05 & 03 \\
\hline
\end{tabular}

In primary cases of autoimmune hemolytic anemia the common presentation was dyspnea on exertion and fatigue. In secondary cases of AIHA common presentation was weight loss, bleeding and joint pain.

All studied patient showed pallor except two cases. Splenomegaly was more common in primary cases.

Table No.2: Clinical Feature and Physical Examination Findings

\begin{tabular}{|c|c|c|c|c|}
\hline \multicolumn{2}{|c|}{ Symptoms } & $\begin{array}{c}\text { Primary cases (no. of } \\
\text { cases showing } \\
\text { following findings) }\end{array}$ & $\begin{array}{c}\text { Secondary cases } \\
\text { (no.of cases showing } \\
\text { following findings) }\end{array}$ & $\begin{array}{c}\text { Total cases } \\
\text { of specific } \\
\text { complaints }\end{array}$ \\
\hline & Fatigue & 13 & 05 & 18 \\
\cline { 2 - 5 } & Dyspnea on exertion & 08 & 06 & 14 \\
\cline { 2 - 5 } & Joint pain & 04 & 09 & 13 \\
\cline { 2 - 5 } & Bleeding & 05 & 10 & 15 \\
\cline { 2 - 5 } & Weight loss & 03 & 03 & 06 \\
\cline { 2 - 5 } & Dizziness & 03 & 04 & 08 \\
\hline
\end{tabular}

The anemia was graded in severity according to hemoglobin reports as below : Those having HB between 10 to $12 \mathrm{mg} / \mathrm{dl}$ considered as mild case, Those having HB between 7 to 10 were labeled as moderate degree anemia and those having HB value less than 7 were considered as severe degree anemia. 
Table No-3: Severity of Anemia in AIHA

\begin{tabular}{|c|c|c|c|}
\hline & Mild anemia & Moderate anemia & Severe anemia \\
\hline Primary AIHA Cases & 03 & 04 & 15 \\
\hline Secondary AIHA Case & 06 & 18 & 08 \\
\hline
\end{tabular}

The other parameters like reticulocytosis, nucleated RBC, Polychromasia etc.were tabulated as below:

Table No.4 : various other parameters in AIHA

\begin{tabular}{|c|c|c|}
\hline Parameters & Primary AIHA & Secondary AIHA \\
\hline Reticulocytosis & 18 & 13 \\
\hline Nucleated RBC & 16 & 03 \\
\hline Polychromasia & 04 & 13 \\
\hline Thrombocytopenia & 05 & 19 \\
\hline Raised LDH & 17 & 02 \\
\hline Increased bilirubin & 22 & 16 \\
\hline
\end{tabular}

Among all DCT positive 60 cases, 10 patients had shown positive ICT also. In our study warm antibody detected cases were $70 \%$ while others were $30 \%$.

\section{Discussion}

In Choudhary et al.study[6] most common clinical feature was pallor followed by fever and jaundice. In our study pallor and jaundice were also common and correlate well but fever was present in only 5 cases in our study. In Choudhary et al. study splenomegaly was present in $81 \%$ and most of cases of AIHA were primary while in our study secondary cases were more as compared to primary and splenomegaly was present in 33 cases $(55 \%)$.

In study done by Serrano J [7] warm antibodies were present in $74.5 \%$ while cold antibodies were present in $19 \%$. In our study also warm AIHA cases were $70 \%$ which correlate well with this study. In Sokol et al.study [8] 95\% cases of warm AIHA showed positive DCT test suggesting that DCT can be implied as diagnostic test for AIHA[9]

Usually AIHA affect red blood cells mainly in which antibodies form against it. Hence White blood cells and platelet should be normal, But in our study platelet count decreased by autoimmune destruction suggesting antibodies might form against platelet as well like in Evans syndrome but affection is less than red blood cells.

In our study autoimmune hemolytic anemia dived into primary and secondary cases but some researchers had divided AIHA in four subtypes including idiopathic, associated cases, secondary, accompanying cases [7]. The study regarding such detail classification needs to be done and evaluated accordingly.

The DCT test considered as effective test for diagnosis of AIHA but if antibodies titers are low than some time DCT can be false negative. Some studies had been done regarding this and found that threshold for IG $G$ molecules should be between 100 to 500 in number to give positive DCT.[10,11].

The several reasons why DCT can be false negative in few cases are as follow.

1. There might be low affinity binding antibodies so that while doing cell washing with normal saline antibodies might washed off. Use of low ionic strength solution LISS can eliminate this problem.

2. Sometime antibody titer might low as discussed above to give positive reaction. For that ELISA and Flow cytometry like higher investigations needs to be done. If antibodies are of IG M or IG A type than it cannot be detected by routine DCT test [12].

In our study to detect positive cases accurately, for reliable result, for stable result and to increase 
sensitivity we have used gel card testing along with manual DCT. The study regarding usefulness of gel card has been done and it proves that gel card having more sensitivity as compared to manual method [13].

According to some studies incidence per year of warm AIHA estimated to be approximately one per 75000 populations. The onset of presentation is usually insidious and not acute in most of cases. Features in primary AIHA are mainly related to anemia but in secondary cases symptoms from underlying disease may be preceding [14].

In our study to perform DCT we have used polyspecific cooms reagent containing anti IG $\mathrm{G}$ and Anti $\mathrm{C} 3$. Whenever IG $\mathrm{M}$ antibodies are present in AIHA patient they fix the complement so that by anti complement action in coombs sera indirectly IG M will be detected. IG A antibodies have never been found without presence of IG G and IG M type antibodies.

Hence in cooms serum no need for use of Anti IG M and Anti IG A as per WHO manual for transfusion medicine [15].

In our study ICT test was also done to detect free antibodies in plasma or serum which might be present in plasma or serum in few cases because there is a dynamic reaction between $\mathrm{RBC}$ and plasma for antibodies and this reaction is reversible. Hence ICT testing also needs to be done [16].

In our case drug induce hemolytic anemia cases were six among all 34 cases of secondary AIHA cases. The common drug we have encountered is ceftriaxone which correlate with study done by Arndt PA et al [17].

Clinical picture in drug induced hemolytic anemia varies according to degree of hemolysis. The history regarding drug exposure therefore should always be elicited in hemolytic anemias. Widespread use of cephalosporin group drug usage for acute infections might be the reason for common drug encountering in drug induced autoimmune hemolytic anemias.

AIHA cases are treated with corticosteroid particularly prednisolone. In steroid non responder cyclophosphamide, azathioprine and cyclosporine like drug given. In selected cases splenectomy can be done. In $30 \%$ case benefit from intravenous $\mathrm{IgG}$ is also noted [1]

\section{Conclusion}

With taking consideration of age, sex, clinical history, physical examination and DCT with laboratory investigation findings help in diagnosis of AIHA. The diagnosis of AIHA should be made accurately as it needs different treatment and special monitoring with clinical follow up. So this type of study should be done to create awareness.

From our study it can be concluded that female having more chance of AIHA (as compared to male) and secondary causes are more common in AIHA with age group between 20 to 30 year have more predilection. It can be concluded from this study that Severity of anemia, jaundice, clinical presentation, degree of hemolysis, splenomegaly are aggressive in primary cases as compared to secondary cases.

Funding: Nil, Conflict of interest: None initiated, Permission from IRB: Yes

\section{References}

1. Singh T. Atlas and text of hematology. Second edition.India New delhi:Avichal publication company;2011.

2. Robert SS, Eugene MB, Leslie ES.Hematology:Basic principles and Practice. $3^{\text {rd }}$ ed.NewYork:Churchill Livingston; 2000.pp.661-730.

3. Agarwal B. Autoimmune hemolytic anemia. Indian J Pediatr. 1998 Sep-Oct;65(5):663-8.

4. COOMBS RR, MOURANT AE, RACE RR. A new test for the detection of weak and incomplete $\mathrm{Rh}$ agglutinins. $\mathrm{Br} \quad \mathrm{J}$ Exp Pathol. 1945; 26: 255-66.

5. Pirofsky B. Clinical aspects of autoimmune hemolytic anemia. Semin Hematol. 1976 Oct; 13 (4):251-65.

6. Choudhary VP,Passi GR,Pati HP. Clinicohematological spectrum of autoimmune hemolytic anemia:An Indian experience.J Assoc Physicians India. 1996;44(2):112-4.

7. Serrano J. [Autoimmune hemolytic anemia. Review of 200 cases studied in a period of 20 years (19701989)]. Sangre (Barc). 1992 Aug;37(4):265-74. 
8. Sokol RJ, Booker DJ, Stamps R. The pathology of autoimmune haemolytic anaemia. J Clin Pathol. 1992 Dec; 45(12):1047-52.

9. Issit P.Serological diagnosis and characterization of causative antibody.In :Chaplin $\mathrm{H}$ Jr,editor.Methods in hematology-Immune hemolytic anemia.USA:Churchill Livingston; 1985.

10. Merry AH,Thomson EE,Rawlinson VI,Stratton F. Quantitation of $\mathrm{IgG}$ on erythrocytes:Correlation of number of IgG molecules per cell with the strength of the direct and indirect antiglobulin tests.Vox Sang.1984;47(6):73-81.

11. Chaplin H, Avioli LV. Grand rounds: autoimmune hemolytic anemia. Arch Intern Med. 1977 Mar; 137 (3):346-51.

12. Vangelen-Taylor V, editor.Technical Manual of American Association of Blood Banks.12 $2^{\text {th }}$
ed.Maryland:Bathesda; 1996.The positive DAT and Immune mediated red cell destruction;pp.379-410.

13. Jaiprakash M, Gupta PK, Kumar H. Role of gel based technique for Coomb's test. Indian J Pathol Microbiol. 2006 Jul;49(3):370-2.

14. Garratty G, Petz LD. Drug-induced immune hemolytic anemia. Am J Med. 1975 Mar;58(3):398-407.

15. Saran RK.Transfusion medicine technical manual.Second ed.India:Directorate general of health services, government of india;2003.

16. S, Bingham M, Boehni P. Autoimmune hemolytic disease. Antibody dissociation and activity. Arch Intern Med. 1961 Sep;108:338-52.

17. Arndt PA, Garratty G. Cross-reactivity of cefotetan and ceftriaxone antibodies, associated with hemolytic anemia, with other: cephalosporins and penicillin. Am J Clin Pathol. 2002 Aug;118(2):256-62.

\section{How to cite this article?}

Goswami P.R, Chaudhary S.B. A clinico hematological correlation of autoimmune hemolytic anemia and its clinical implication. Int J Med Res Rev 2016;4(10):1791-1795.doi:10.17511/ijmrr. 2016.i10.14. 